\title{
Effect of The Enzyme Charge On The Production And Morphological Characteristics of Cellulose Nanofibrils
}

\section{Sergio Henríquez-Gallegos}

Universidad de Concepcion

\section{Gregory Albornoz-Palma}

Universidad de Concepción: Universidad de Concepcion

\section{Andrea Andrade}

Universidad de Concepcion

\section{Carolina Soto}

Universidad de Concepcion

Miguel Pereira ( $\nabla$ miguelpereira@udec.cl)

Universidad de Concepción https://orcid.org/0000-0003-0618-6259

\section{Research Article}

Keywords: cellulose nanofibrils, enzymatic hydrolysis, degree of polymerization, fibrillation process, morphology

Posted Date: May 26th, 2021

DOI: https://doi.org/10.21203/rs.3.rs-472299/v1

License: (c) (1) This work is licensed under a Creative Commons Attribution 4.0 International License. Read Full License 


\section{Abstract}

The effect of cellulase enzymes on the degree of polymerization of cellulose and the mechanical fibrillation process has been widely reported. However, the available information does not allow to establish specific relationships between the applied enzymatic-mechanical treatment, the degree of polymerization, and the characteristics of the cellulose nanofibrils (CNFs) produced. This work aims to establish specific relationships between the intensity of enzymatic treatment, the degree of polymerization of the cellulose, the morphology of CNFs, and the tensile strength of the films. It was determined that the decrease in the degree of polymerization plays an important role in the fibrillation processes of the cell wall to produce CNFs and that there is a linear relationship between the degree of polymerization and the length of CNFs, which is independent of the type of enzyme, enzyme charge, and intensity of the applied mechanical treatment. In addition, it was determined that the percentage of decrease in the degree of polymerization of CNFs due to mechanical treatment is irrespective of the applied enzyme charge. Else ways, it was shown that the aspect ratio is a good indicator of the efficiency of the fibrillation process, and the degree of polymerization in not. Finally, it was shown that the resistance of CNF films is positively related to the degree of polymerization up to a maximum value which corresponds to the maximum of the aspect ratio.

\section{Introduction}

Due to abundance and sustainability, plant cellulose and cellulosic nanomaterials have attracted increasing interest as an alternative to synthetic materials, especially as fillers and reinforcement for composite materials (Qing et al., 2013). Cellulose nanomaterials (CNM) comprise a broad spectrum of materials produced by the deconstruction of the cell wall. Due to the surprising and promising characteristics of cellulose nanomaterials: biocompatible and transparent material, excellent mechanical behavior at low weight, and very reactive due to the hydroxyl groups present on its surface (Lavoine et al., 2012; Grüneberger et al., 2014; Nechyporchuk et al., 2016) several researchers have focused their interest on the study of this nanomaterial and its potential uses at an industrial level: coating, polymeric reinforcement, 3D printing, rheological modifier, among others (Heggset et al. 2017; Albornoz-Palma et al. 2020b). The term " cellulose nanofibrils (CNF) " refers to fibrils with nanoscale widths (less than $100 \mathrm{~nm}$ ) (ISO 2017), whose average length values are estimated in the order of several micrometers (Tanaka et al., 2015).

In previous decades, the challenge associated with the isolation of CNFs was to reduce the high energy demand required by the mechanical fibrillation process, reporting values between 5 y $70 \mathrm{kWh} / \mathrm{kg}$ (Spence et al., 2011). However, with the incorporation of pretreatment methods, such as chemical pretreatments (carboxymethylation, carboxylation, quaternization, sulfonation, and oxidation) or enzymatic pretreatments, energy consumption and production costs decreased, making CNFs a more attractive material for commercial applications (Saito et al., 2006; Siró and Plackett 2010; Nechyporchuk et al., 2016). However, research continues to focus on optimizing existing techniques and developing 
alternative methods that can benefit the production process or provide CNFs with new properties (Nechyporchuk et al., 2016).

The use of cellulase enzymes as pretreatment for the production of CNF has been one of the most studied, since it favors the process of deconstruction of the cell wall, reduces energy consumption, and facilitates the production of nanofibrils with more homogeneous and controlled dimensions (Pääkkö et al., 2007; Delgado-Aguilar, 2015; Tarrés et al., 2016; Hu et al., 2018). In addition, with the use of enzymatic hydrolysis, high yields are favored, the environmental impact is reduced, and it is possible to produce materials suitable for biomedical applications (Ribeiro et al., 2019).

Cellulases are groups of enzymes that catalyze the breakdown of cellulose polymer into smaller polymer chains or even cellobiose and glucose. Traditionally, these enzymes are divided into three groups: endoglucanase, exo--1,4-glucanase or cellobiohydrolase (CBH), and -glucosidase (cellobiase) (Bhat and Bhat 1997). In terms of CNFs production with enzymatic pretreatment, endoglucanases are the most interesting, considering their action is randomly focused on the amorphous regions of cellulose (specifically on the $\beta-1,4$ bonds corresponding to $\mathrm{C} 1$ of the first glucose unit and $\mathrm{C} 4$ of the after unit), breaking the cellulose chain into polymers of shorter length (Delgado-Aguilar, 2015; Ribeiro et al., 2019). Nechyporchuk et al. (2015) compared CNF production using monocomponent endoglucanases and a mixture of endoglucanase, exo- -1,4-glucanase, and cellobiase and showed that monocomponent endoglucanase has a better effect on the separation of nanofibrils while inducing less depolymerization of cellulosic chains.

The degree of polymerization (DP) is defined as the number of times that the monomeric unit that forms the polymer chain repeats (Delgado-Aguilar 2015). This is an important parameter that evaluates the length of cellulose chains and is frequently used to evaluate produced CNFs (Qing et al., 2013). Endoglucanases randomly cleave amorphous regions of cellulose chains and are characterized by drastically decreasing the degree of polymerization, but they slowly release soluble sugars from crystalline regions (Ek et al., 2009).

The effect of cellulase enzymes on the degree of polymerization of cellulose and the mechanical fibrillation process has been widely reported (Henriksson et al., 2007; Pääkkö et al., 2007; Qing et al., 2013; Karim et al., 2014; Tarrés et al., 2016; Hu et al., 2018; Albornoz-Palma et al., 2020a; Andrade et al., 2021). However, the available information does not allow to establish specific relationships between the enzymatic-mechanical treatment applied, the degree of polymerization and the characteristics of the CNFs. This work aims to establish specific relationships between the intensity of enzymatic treatment, the degree of polymerization of the cellulose, the morphology of CNFs (for a fixed amount of energy), and the tensile strength of the films.

\section{Material And Methods}

\subsection{Raw material}


The bleached Kraft hardwood pulp (80\% Eucalyptusglobulus and 20\% Eucalyptus nitens) used for the production of CNFs was provided by the company CMPC pulp S.A. (Santa Fe Mill, Chile). Pulp was rehydrated, filtered and pelleted according to ISO 5263. The chemical characterization of cellulosic fibers was performed through acid hydrolysis based on the method described by Mendonça et al. (2008) and Andrade et al. (2021).

The enzymatic hydrolysis was performed using the commercial enzyme complex of cellulases Quimizime $\mathrm{B}$, provided by $\mathrm{CHT}$ group Chile which a higher content of endoglucanases and an activity of $7,75 \mathrm{U} / \mathrm{ml}$ enzyme. Enzyme activity was determined according to methodology of Ghose (1987).

\subsection{Production of cellulose nanofibrils}

\subsubsection{Mechanical-enzymatic pretreatment}

30 dry grams of Kraft bleached eucalyptus pulp (BHKP) at $10 \mathrm{wt} \%$ were refined in a PFI mill at 4,000 revolutions with the aim of increasing the accessibility of the enzyme in the substrate. Then, $0.05 \%$ of Quimizime B enzyme was added with respect to the dry weight of the pulp. The enzymatic pretreatment conditions were $70 \mathrm{~min}$ of reaction, temperature of $48^{\circ} \mathrm{C}, 5 \%$ consistency, pH 5 (adjusted with $0.1 \mathrm{M} \mathrm{HCl}$ ), and constant stirring at $800 \mathrm{rpm}$ with a Stirrer Type BS. After the reaction time, the enzyme was denatured at $80^{\circ} \mathrm{C}$ for 20 minutes. The pulp was refined at 46,000 revolutions in a PFI mill at $10 \%$ consistency. After the mechanical treatment, the pulp was separated and subjected to 5 enzymatic pretreatments with the same conditions of the first enzyme pretreatment, varying only the enzyme percentage: $0 \%, 0.025 \%$, $0.05 \%, 0.075 \%$, and $0.1 \%$ with respect to the dry weight of the pulp.

\subsubsection{High pressure homogenization}

Suspensions in water of the treated fibers were prepared, according to the sequence of mechanical and enzymatic pretreatments described in point 2.2 .1 at a consistency of $0.5 \%$. These were subjected to a homogenization process at a pressure 700 bar in a Gea Niro Soavi Panda Plus 2000 homogenizing equipment provided with S-type impact head. The treatment consists of passing the fiber suspension through the equipment 15 times, in order to produce 5 types of CNFs that differed only in the enzyme charge of the second enzyme pretreatment

\subsection{Characterization of cellulose nanofibrils}

\subsubsection{Enzymatic degradation of pulp}

The enzymatic degradation was evaluated through two indicators: (1) Quantification of carbohydrates present in the filtrate: To determine the effect of the enzyme on cellulosic fibers, the carbohydrates present in the hydrolyzed filtrate were quantified, according to the methodology presented by Ferraz et al. (2000) and Aguayo et al. (2010). (2) Degree of polymerization: The degree of polymerization of cellulose was determined by measuring the intrinsic viscosity in cuproethylene diamine according to Chakraborty et al. (2006). 


\subsubsection{Transmittance of CNF dispersions}

The transmittance was determined on CNF dispersions at $0.1 \%$, using a Genesys UV10 spectrophotometer, at a wavelength of $800 \mathrm{~nm}$, using distilled water as a reference, according to the methodology presented by Delgado-Aguilar (2015).

\subsubsection{Intrinsic viscosity}

Intrinsic viscosity was determined from the viscosities of CNF dispersions, according to Albornoz-Palma et al. (2020a). For measurements, a Brookfield LVDV-I + viscometer was used with a ULA spindle (Ultra Low Adapter) spindle, which configuration corresponds to a double-cylinder geometry, from sample at different concentrations $(0.02 \%(\mathrm{w} / \mathrm{v})$ to $0.08 \%(\mathrm{w} / \mathrm{v}))$. Each of the samples was heated in a Julabo SW22 thermal bath at $23^{\circ} \mathrm{C}$ for 2 hours before the measurement. Samples did not show thixotropic behavior and reached a steady state in less than $20 \mathrm{~s}$. The measurement conditions were to $23^{\circ} \mathrm{C}$ and shear rate of $73.38 \mathrm{~s}^{-1}$.

\subsubsection{Morphological characteristics of CNFs}

The average length of CNF dispersions ( $\mathrm{L}^{-}$) was measured using S3500 Laser Diffraction Particle Size Analyzer (Microtrac Inc. USA) (refractive index: 1.54 (Hinestroza et al., 2014)) from dispersions at $0.04 \%$ (w/v) consistency, according to Albornoz-Palma et al. (2020a). Each sample was sonicated for $60 \mathrm{~s}$, in the equipment before measurement, to eliminate entanglements and aggregates that could have formed.

The aspect ratio $\left(\mathrm{L}^{-} / \mathrm{d}^{\top}\right)$ and the average width $\left(\mathrm{d}^{\top}\right)$ was calculated from the relationship between the intrinsic viscosity CNF dispersions ([n]) and the average length of CNFs (Albornoz-Palma, 2020a):

$p[\eta]=0.051 p^{1.85}$

where $p$ is the density of NFCs $(1.6 \mathrm{~g} / \mathrm{ml})$ and is the aspect ratio of $\mathrm{CNFs}\left(\mathrm{L}^{-} / \mathrm{d}\ulcorner)\right.$.

\subsubsection{Mechanical properties of CNFs}

The maximum load stress $(\mathrm{N})$ supported by rectangular samples $(2 \mathrm{~cm}$ wide, $8 \mathrm{~cm}$ long) made from CNFs films $\left(30 \mathrm{~g} / \mathrm{m}^{2}\right)$ was determined in the tension testing equipment (TestResources Inc, USA). The separation of the clamps in the specimens during the measurement was $2 \mathrm{~cm}$.

\section{Results And Discussion}

\subsection{Mechanical-enzymatic pretreatment}

Cellulolytic enzymes are glucoside hydrolases that break the $\beta$-(1à4)-glucosidic bonds of carbohydrates by inversion or retention of the anomeric carbon configuration (Ek et al. 2009). 
Table 1 shows the percentage distribution of the solid residue and the fraction of solubilized carbohydrates from the eucalyptus pulp after the enzymatic pretreatments. As expected, the enzyme complex solubilized part of the hemicelluloses and cellulose of the raw material, whose initial chemical composition was: $77.7 \pm 0.5 \%$ cellulose, $21.1 \pm 0.5 \%$ hemicellulose and lignin $<1 \%$, which coincides with what reported by other authors for this type of pulp (Hu et al., 2018; Carrillo-Varela et al., 2019; Andrade et al., 2021). The first enzymatic treatment ( $\left.2^{\circ}-0.000 \%\right)$, which was identical for the $5 \mathrm{CNFs}$, solubilized a lower amount of cellulose and xylan than the pulps with double enzymatic treatment, so the carbohydrate yield in the solid fraction was higher. This is due to the fact that in the first enzyme treatment the accessibility of the enzyme to the substrate was lower than the second. Both the mechanical refining process, as well as the first enzymatic treatment caused greater internal and external fibrillation of the fibers, increasing the exposed surface area of the fiber and the absorption of water, which facilitated the accessibility of the enzyme for second hydrolysis enzymatic.

The percentage of carbohydrates in the solid fraction decreases as the enzyme charge of the second enzyme treatment increases from $0 \%$ to $0.1 \%$, which is mainly due to the hydrolysis of amorphous cellulose (Pääkko et al., 2007). Furthermore, in the second enzymatic treatment, the degradation of xylans was statistically the same for all samples, so the difference in the decrease in solid yields is clearly due to the hydrolysis of cellulose.

Table 1. Enzymatic hydrolysis and solubilization of carbohydrates.

\begin{tabular}{|c|c|c|c|c|}
\hline \multirow[t]{3}{*}{ Pulp } & \multirow{3}{*}{$\begin{array}{l}\text { Enzyme charge } \\
\text { a }\end{array}$} & \multicolumn{2}{|c|}{ Solubilized compounds } & \multirow{3}{*}{$\begin{array}{l}\text { Solid carbohydrate yield } \\
(\%)\end{array}$} \\
\hline & & Cellulose & Xylan & \\
\hline & & $\begin{array}{l}\text { (\% initial } \\
\text { cellulose) }\end{array}$ & $\begin{array}{l}\text { (\% initial } \\
\text { xylan) }\end{array}$ & \\
\hline \multirow[t]{5}{*}{ Eucalyptus } & $2^{\circ}-0.000 \%$ & $1.9 \pm 0.1$ & $1.5 \% \pm 0.3$ & $96.6 \pm 0.4$ \\
\hline & $2^{\circ}-0.025 \%$ & $3.1 \pm 0.1$ & $3.4 \% \pm 0.2$ & $93.5 \pm 0.2$ \\
\hline & $2^{\circ}-0.050 \%$ & $3.6 \pm 0.2$ & $3.2 \% \pm 0.2$ & $93.2 \pm 0.3$ \\
\hline & $2^{\circ}-0.075 \%$ & $4.3 \pm 0.1$ & $3.2 \% \pm 0.2$ & $92.5 \pm 0.1$ \\
\hline & $2^{\circ}-0.100 \%$ & $4.6 \pm 0.1$ & $3.1 \% \pm 0.1$ & $92.3 \pm 0.2$ \\
\hline
\end{tabular}

a Enzyme charge of the second enzyme treatment.

\subsection{Cellulose nanofibrils production}

Determining the morphological characteristics of CNFs is relevant to understand the final properties of this nanomaterial. Table 2 shows the morphological characteristics of the CNFs produced from pulps with different enzyme charges and the same mechanical treatment. Regarding the width, length, and degree of polymerization of the CNFs, a decrease in these characteristics is observed as the enzyme 
charge increases, which can be attributed to a greater hydrolysis of the cellulose chains due to an increase enzyme concentration. Endoglucanases decrease drastically the degree of polymerization, which would increase the frequency of rupture or breakpoints within the fibers, facilitating the access of water to the interior of the cell wall and consequently the process of mechanical fibrillation.

Table 2. Morphological characteristics of CNFs.

\begin{tabular}{|llllll|}
\hline & $\begin{array}{l}\text { Length } \\
(\mu \mathrm{m})\end{array}$ & $\begin{array}{l}\text { Width } \\
(\mathrm{nm})\end{array}$ & $\begin{array}{l}\text { Aspect } \\
\text { ratio }\end{array}$ & $\begin{array}{l}\text { Transmittance } \\
(\%)\end{array}$ & $\begin{array}{l}\text { Degree of } \\
\text { polymerization }\end{array}$ \\
\hline $\mathrm{CNF}_{0}$ & 8.5 & 32.7 & 260.0 & 73.6 & 447 \\
\hline $\mathrm{CNF}_{0,025}$ & 7.4 & 26.9 & 275.0 & 74.1 & 400 \\
\hline $\mathrm{CNF}_{0,050}$ & 7.1 & 22.9 & 310.9 & 77.1 & 362 \\
\hline $\mathrm{CNF}_{0,075}$ & 6.1 & 21.8 & 278.9 & 78.5 & 334 \\
\hline $\mathrm{CNF}_{0,100}$ & 5.7 & 21.1 & 271.5 & 85.9 & 278 \\
\hline
\end{tabular}

The transmittance of light at a specific wavelength through a CNF suspension indicates the presence of smaller and/or more homogeneous nano-objects and is often used as an indirect method to estimate the degree of fibrillation of CNF dispersions (Delgado-Aguilar, 2015; Tarrés et al., 2016). According to the above, the results of Table 2 show that the increase in the enzyme charge effectively allows greater fibrillation of the BHKP, which is reflected in the decrease in the lengths and widths of the CNFs. From a technological point of view, it is often interesting to produce fibrils with morphological characteristics that favor certain applications. For example, it is expected that a higher aspect ratio will favor the reinforcing properties of composite materials.

When observing the aspect ratio of the nanofibrils (Table 2) it can be clearly seen that this parameter does not have the same tendency as the transmittance of light and that its variation is affected by the enzyme charge during treatment, increasing with the enzyme charge a maximum value and then decreases. With the aim of getting a better understanding of how enzyme charge affects the morphological characteristics of CNFs, the relationships are shown in Figure 1.

For the length of the CNFs (Figure 1a) a negative linear relationship with the enzyme charge is observed, whose differences are statistically significant between the different samples (LSD method, 95\% confidence). These results prove that a higher enzyme charge can generate significant changes in the lengths of the CNFs for the same mechanical treatment. In this case, a charge of $0.1 \%$ of enzyme (in the second enzymatic treatment) generates a 33\% decrease in CNFs lengths.

As mentioned by Taheri and Samyn (2016), the minimum width of the fibrils produced during fibrillation depends on the operating conditions and the equipment used for mechanical fibrillation. Analyzing the widths of the CNFs (Figures 1b), it is observed that there is a drastic and significant decrease ( $p$ value 
$<0.05)$ at low enzyme charges $(<0.0005 \mathrm{ml} / \mathrm{g})$. For enzyme charges greater than $0.0005 \mathrm{ml} / \mathrm{g}$, the decrease in width is much less pronounced and there are no statistically significant differences (LSD method, 95\% confidence). These results suggest that, for the same mechanical treatment, an increase in the enzyme charge facilitates fibrillation up to the minimum width given by the equipment. In this sense, there is evidence of the need to define a control parameter that encompasses the morphological properties of CNFs and optimize the enzymatic pretreatments for each mechanical process.

The morphological parameter that best reflects the concept of fibrillation corresponds to the aspect ratio of the CNFs, since it has been shown that an increase of the enzyme charge favors fibrillation as a result of the transversal break of the fibrils, reducing the length of these, and the longitudinal break that decrease the width until a minimum value. As a consequence of the above, the aspect ratio of the CNFs presents a maximum $(p=311)$ (Figure 1c) for an enzyme charge, in the second enzyme treatment, of $0.0005 \mathrm{ml} / \mathrm{g}$.

An efficient fibrillation process seeks to produce a homogeneous material, with small widths ( $<50 \mathrm{~nm})$, and attempting to decrease transversal break of the fibrils (length). Therefore, the aspect ratio is the parameter that best reflects these characteristics and corresponds to a good indicator of the effectiveness of the fibrillation process.

On one hand, Andrade et al. (2021) determined that for CNFs produced from the same raw material and with the same enzymatic-mechanical treatment, the aspect ratio was 330. On the other hand, AlbornozPalma et al. (2020a) in their study produced CNFs with an aspect ratio of 303, from the same raw material and mechanical treatment, but with a different type and charge of enzyme.

\subsection{Effect of mechanical-enzymatic treatment on the degree of polymerization of cellulose}

The degree of polymerization is an important parameter that evaluates the length of cellulose chains and is frequently used to evaluate CNFs (Qing et al., 2013). Table 3 shows the variation in the degree of polymerization as a function of the applied treatment. As mentioned above, endoglucanase enzymes are characterized by a rapid decrease in the degree of polymerization (Ek et al. 2009).

The "Variation 1" in Table 3 indicates the decrease in DP with respect to the initial raw material $(\mathrm{P})$, which decreases as the intensity of the mechanical and/or enzymatic pretreatment applied increases. The DP of cellulose decreases between 72 and $81 \%$ for the CNF produced, with DP values between 278 and 447, which coincides with that reported by various authors who produced CNF with similar enzymatic and mechanical pretreatments. Albornoz-Palma et al. (2020a) in their study used cellulase enzymes (1.2 wt\%) to produce CNF with a degree of polymerization of 228; Tarres et al. (2016) used endoglucanase enzyme $(0.032 \%)$ to produce CNF with a DP of 309; and Andrade et al. (2021) used the same raw material and enzyme cocktail, charge $0.1 \%$ of enzyme in two treatments ( $0.05 \%$ each) producing CNFs with a DP of 303 , which means a decrease with respect to the initial raw material of $75 \%$. Additionally, Qing et al. (2013) used a different mechanical treatment (SuperMassCollider-Microfluidization 15 passes at 1500 bar) and produced CNFs with a DP of 280 when dosing 3 FPU of enzyme/g fiber. From the above, it 
seems that the lower limit of the degree of polymerization is 220 for CNFs with enzymatic pretreatment with a high degree of fibrillation.

Table 3. Variation in degree of polymerization depending on the treatment applied.

\begin{tabular}{|llll|}
\hline Sample & Degree of polymerization & Variation 1 & Variation 2 \\
\hline$P$ & 1438 & - & \\
\hline$P E$ & 1231 & $-14 \%$ & \\
\hline$P_{0}$ & 916 & $-36 \%$ & \\
\hline$P_{0,25}$ & 649 & $-47 \%$ & \\
\hline$P_{0,05}$ & 601 & $-55 \%$ & \\
\hline$P_{0,075}$ & 529 & $-58 \%$ & \\
\hline$P_{0,1}$ & 497 & $-63 \%$ & \\
\hline $\mathrm{CNF}_{0}$ & 447 & $-65 \%$ & $-41 \%$ \\
\hline $\mathrm{CNF}_{0,025}$ & 400 & $-69 \%$ & $-38 \%$ \\
\hline $\mathrm{CNF}_{0,050}$ & 362 & $-72 \%$ & $-40 \%$ \\
\hline $\mathrm{CNF}_{0,075}$ & 334 & $-75 \%$ & $-44 \%$ \\
\hline $\mathrm{CNF}_{0,100}$ & 278 & $-77 \%$ & $-81 \%$ \\
\hline
\end{tabular}

The "Variation 2" in Table 3 represents the decrease in the DP of the CNF after the homogenization process, with respect to the pulps with mechanical-enzymatic pretreatment. The results show that the decrease in DP due to the homogenization process is independent of the enzyme charge, since for the same mechanical treatment ( 15 passes through the homogenizer) the decrease in DP is close to $40 \%$ for all cases.

The length of the CNFs (Figure 2a) is linearly related to the degree of polymerization, with a coefficient of determination of 0.95 . This line relationship: $L(\mu \mathrm{m})=0.02 \mathrm{DP}$ coincides with that reported by AlbornozPalma et al. (2020a), which produced CNFs with enzymatic pretreatment, but used another enzymes cocktail of cellulase enzymes and a higher enzyme charge $(0.012 \mathrm{ml} / \mathrm{g})$. The authors related the degree of polymerization of their samples to different number of passes through the homogenizer $(0,1,2,4,7$, $10,15)$, showing the same linear regression. In view of the above, the length of the CNFs and the DP are linearly related, independent of the type of cellulase enzyme, enzymatic charge and intensity of the mechanical treatment applied. 
As the relationship between length and degree of polymerization is positive linear (Figure 2a) and the relationship between length and enzyme charge is negative linear (Figure 1a), width and aspect ratio show the same trends as a function of the degree of polymerization than with the enzymatic charge, but in a specular way. Because of the above, the width of the CNFs (Figure 2b) at DP less than 362 did not show statistically significant differences (LSD method, 95\% confidence). On the other hand, at DP greater than 362 , the differences are significant, and the DP of the samples varies by up to $38 \%$. The relationship between the aspect ratio and the DP has a maximum at DP $=362$ (Figure 2c). This maximum is due to the fact that DP less than 362 there is a change in the lengths of CNFs but not in the widths, so the aspect ratio decreases.

In the literature, it has been observed that a higher degree of polymerization is strongly related to the improvement in the mechanical properties of nanofibrils (Zimmermann et al., 2010; Tarrés et al., 2016). Regarding the maximum load supported by the CNFs films (Figure 2d), it is observed that for DP values greater than 362, there are no statistically significant differences (Bonferroni method, $95 \%$ confidence). For DP less than 362 , the maximum load decreases, and the values are statistically different (Bonferroni method, $95 \%$ confidence). When relating these results to the enzymatic charge and the aspect ratio, it can be seen that for charges less than or equal to $0.0005 \mathrm{ml} / \mathrm{g}$ (DP 362), where the aspect ratio is increasing to its maximum, the resistance of the CNF films remains constant. For enzyme charges greater than or equal to $0.0005 \mathrm{ml} / \mathrm{g}$ (DP 362), where the aspect ratio is decreasing, the resistance of the CNF films decreases. The above shows that the resistance of CNFs films is positively related to the degree of polymerization up to a maximum value, which corresponds to the maximum value of the aspect ratio. This is why the aspect ratio is the parameter that best predicts the final mechanical properties of the CNFs.

\section{Conclusions}

The enzymatic pretreatment facilitates the deconstruction of the cell wall of the fibers. However, at high enzyme charges, the aspect ratio of the CNFs shows a drastic decrease, due to inefficient fibrillation due to the transversal break of CNFs.

Moreover, it was shown that the DP is linearly related to the length of the CNFs, independent of the type of cellulase enzyme, enzymatic charge, and intensity of the mechanical treatment applied. Furthermore, the percentage decrease in DP, for the same intensity in the mechanical treatment, is independent of the enzymatic charge.

Finally, the maximum load supported by CNF films is linearly related to the DP up to a maximum value, corresponding to the maximum value of the aspect ratio. The aspect ratio proved to be the parameter that best reflects the final mechanical properties of the CNFs and the efficiency of the fibrillation process.

\section{Abbreviations}




\begin{tabular}{|c|c|}
\hline Nomenclature & Characteristics \\
\hline$P$ & $\mathrm{BHKP}$ \\
\hline PR & $\mathrm{BHKP}-4,000$ rev PFI \\
\hline PE & BHKP $-4,000$ rev $\mathrm{PFI}-0,05 \%$ \\
\hline$P_{0}$ & BHKP - 4,000 rev PFI - 0,05\% - 46,000 rev PFI - 0\% \\
\hline$P_{0,25}$ & BHKP - 4,000 rev PFI - 0,05\% - 46,000 rev PFI - 0,025\% \\
\hline$P_{0,05}$ & BHKP - 4,000 rev PFI - 0,05\% - 46,000 rev PFI - 0,05\% \\
\hline$P_{0,075}$ & BHKP - 4,000 rev PFI - 0,05\% - 46,000 rev PFI - 0,075\% \\
\hline$P_{0,1}$ & BHKP - 4,000 rev PFI - 0,05\% - 46,000 rev PFI - 0,1\% \\
\hline $\mathrm{CNF}_{0}$ & BHKP $-4,000$ rev $P F I-0,05 \%-46,000$ rev $P F I-0 \%-15$ pass \\
\hline $\mathrm{CNF}_{0,025}$ & BHKP - 4,000 rev PFI - 0,05\% - 46,000 rev PFI - 0,025\% - 15 pass \\
\hline $\mathrm{CNF}_{0,050}$ & BHKP - 4,000 rev PFI - 0,05\% - 46,000 rev PFI - 0,05\% - 15 pass \\
\hline $\mathrm{CNF}_{0,075}$ & BHKP - 4,000 rev PFI - 0,05\% - 46,000 rev $\mathrm{PFI}-0,075 \%-15$ pass \\
\hline $\mathrm{CNF}_{0,100}$ & BHKP $-4,000$ rev $\mathrm{PFI}-0,05 \%-46,000$ rev $\mathrm{PFI}-0,1 \%-15$ pass \\
\hline
\end{tabular}

\section{Declarations}

\section{Funding}

The research was funding by ANID-Subdirección de Capital Humano/Doctorado Nacional/202021202153, ANID-Subdirección de Capital Humano/Doctorado Nacional/2018-21181080, and project FONDECYT N 1201042.

\section{Conflicts of interest/Competing interests}

This research has no conflicts of interest

\section{Availability of data and material/ Code availability}

The data and codes information will not be uploaded to the repository.

\section{Author contributions}

Sergio Henríquez-Gallegos: Conceptualization, Methodology, Formal analysis, Investigation, Writing. Gregory Albornoz-Palma: Formal analysis, Investigation, Writing - Original Draft. Andrea Andrade: 
Conceptualization, Methodology, Investigation. Carolina Soto: Methodology, Formal analysis. Miguel

Pereira: Validation, Resources, Writing - Review \& Editing, Supervision, Funding acquisition.

\section{ACKNOWLEDGMENT}

S. Henríquez-Gallegos thanks the Dirección de Postgrado de la Universidad de Concepción for granting a scholarship for the development of him postgraduate studies. ANID-Subdirección de Capital Humano/Doctorado Nacional/2020-21202153, ANID-Subdirección de Capital Humano/Doctorado Nacional/2018-21181080, the ASIF laboratory (Departamento de Ingeniería Química, Universidad de Concepción), Eng. Carlos Oliveros, and project FONDECYT №1201042.

\section{References}

1. Aguayo, M. G., Quintupill, L., Castillo, R., Baeza, J., Freer, J., \& Mendonça, R. T. (2010). Determination of differences in anatomical and chemical characteristics of tension and opposite wood of 8-yearold Eucalyptus globulus. Maderas. Ciencia y tecnologia, 12(3), 241-251.

2. Albornoz-Palma, G., Betancourt, F., Mendonça, R. T., Chinga-Carrasco, G., \& Pereira, M. (2020a). Relationship between rheological and morphological characteristics of cellulose nanofibrils in dilute dispersions. Carbohydrate Polymers, 115588.

3. Albornoz-Palma, G., Ching, D., Valerio, O., Mendonça, R. T., \& Pereira, M. (2020b). Effect of lignin and hemicellulose on the properties of lignocellulose nanofibril suspensions. Cellulose, 1-17.

4. Andrade, A., Henríquez-Gallegos, S., Albornoz-Palma, G., \& Pereira, M. (2021). Effect of the chemical and structural characteristics of pulps of Eucalyptus and Pinus on the deconstruction of the cell wall during the production of cellulose nanofibrils. Cellulose, 1-13.

5. Bhat, M. K., \& Bhat, S. (1997). Cellulose degrading enzymes and their potential industrial applications. Biotechnology advances, 15(3-4), 583-620.

6. Carrillo-Varela, I., Retamal, R., Pereira, M., \& Mendonça, R. T. (2019). Structure and reactivity of cellulose from bleached kraft pulps of different Eucalyptus species upgraded to dissolving pulp. Cellulose, 26(9), 5731-5744.

7. Chakraborty, A., Sain, M., \& Kortschot, M. (2006). Reinforcing potential of wood pulp-derived microfibres in a PVA matrix. Holzforschung, 60(1), 53-58.

8. Delgado Aguilar, M. (2015). Nanotecnología en el sector papelero: mejoras en calidad y permanencia de las fibras de alto rendimiento y secundarias en una economía circular mediante el uso de nanofibras y el refino enzimático.

9. Ek, M., Gellerstedt, G., \& Henriksson, G. (Eds.). (2009). Wood chemistry and biotechnology (Vol. 1). Walter de Gruyter.

10. Ferraz, A., Baeza, J., Rodriguez, J., \& Freer, J. (2000). Estimating the chemical composition of biodegraded pine and eucalyptus wood by DRIFT spectroscopy and multivariate analysis. Bioresource Technology, 74(3), 201-212. 
11. Ghose, T. K. (1987). Measurement of cellulase activities, Pure and Applied Chemistry, 59 (2), 257-268.

12. Hinestroza, J., \& Netravali, A. N. (2014). Cellulose based composites: new green nanomaterials. John Wiley \& Sons.

13. Heggset, E. B., Chinga-Carrasco, G., \& Syverud, K. (2017). Temperature stability of nanocellulose dispersions. Carbohydrate polymers, 157, 114-121.

14. Henriksson, M., Henriksson, G., Berglund, L. A., \& Lindström, T. (2007). An environmentally friendly method for enzyme-assisted preparation of microfibrillated cellulose (MFC) nanofibers. European Polymer Journal, 43(8), 3434-3441.

15. Hu, J., Tian, D., Renneckar, S., \& Saddler, J. N. (2018). Enzyme mediated nanofibrillation of cellulose by the synergistic actions of an endoglucanase, lytic polysaccharide monooxygenase (LPMO) and xylanase. Scientific reports, 8(1), 1-8.

16. ISO 5263-1. (2004). Pulps-Laboratory wet disintegration-Part 1: Disintegration of chemical pulps.

17. ISO ISO/TS (2017) 20477:2017 Nanotechnologies-Standard terms and their definition for cellulose nanomaterial. ISO, Geneva.

18. Lavoine, N., Desloges, I., Dufresne, A., \& Bras, J. (2012). Microfibrillated cellulose-lts barrier properties and applications in cellulosic materials: A review. Carbohydrate polymers, 90(2), 735-764.

19. Mendonça, R.T., Jara, J.F., Gonzalez, V., Elissetche, J.P., Freer, J., (2008). Evaluation of white root fungi Ganoderma australe and Ceriporiopsis subvermispora in biotechnological applications. Journal of Industrial Microbiology and Biotechnology. 35, 1323-13.

20. Nechyporchuk, O., Pignon, F., \& Belgacem, M. N. (2015). Morphological properties of nanofibrillated cellulose produced using wet grinding as an ultimate fibrillation process. Journal of Materials Science, 50(2), 531-541.

21. Nechyporchuk, O., Belgacem, M. N., \& Bras, J. (2016). Production of cellulose nanofibrils: A review of recent advances. Industrial Crops and Products, 93, 2-25.

22. Pääkkö, M., Ankerfors, M., Kosonen, H., Nykänen, A., Ahola, S., Österberg, M., ... \& Lindström, T. (2007). Enzymatic hydrolysis combined with mechanical shearing and high-pressure homogenization for nanoscale cellulose fibrils and strong gels. Biomacromolecules, 8(6), 1934-1941.

23. Qing, Y., Sabo, R., Zhu, J. Y., Agarwal, U., Cai, Z., \& Wu, Y. (2013). A comparative study of cellulose nanofibrils disintegrated via multiple processing approaches. Carbohydrate polymers, 97(1), 226234.

24. Saito, T., Nishiyama, Y., Putaux, J. L., Vignon, M., \& Isogai, A. (2006). Homogeneous suspensions of individualized microfibrils from TEMPO-catalyzed oxidation of native cellulose. Biomacromolecules, 7(6), 1687-1691.

25. Siró, I., \& Plackett, D. (2010). Microfibrillated cellulose and new nanocomposite materials: a review. Cellulose, 17(3), 459-494.

26. Spence, K. L., Venditti, R. A., Rojas, O. J., Habibi, Y., \& Pawlak, J. J. (2011). A comparative study of energy consumption and physical properties of microfibrillated cellulose produced by different 
processing methods. Cellulose, 18(4), 1097-1111.

27. Stoere, P., Nazhad, M., \& Kerekes, R. J. (2001). An experimental study of the effect of refining on paper formation. Tappi journal, 84(7).

28. Tanaka, R., Saito, T., Hondo, H., \& Isogai, A. (2015). Influence of flexibility and dimensions of nanocelluloses on the flow properties of their aqueous dispersions. Biomacromolecules, 16(7), 21272131.

29. Taheri H, Samyn $P$ (2016) Effect of homogenization (microfluidization) process parameters in mechanical pro- duction of micro and nanofibrillated cellulose on its rheological and morphological properties. Cellulose 23(2):1221-1238.

30. Tarrés, Q., Saguer, E., Pèlach, M. A., Alcalà, M., Delgado-Aguilar, M., \& Mutjé, P. (2016). The feasibility of incorporating cellulose micro/nanofibers in papermaking processes: the relevance of enzymatic hydrolysis. Cellulose, 23(2), 1433-1445

31. Tokimatsu, K., Tamura, S., \& Kojima, H. (1992). Effects of multiple modes on Rayleigh wave dispersion characteristics. Journal of geotechnical engineering, 118(10), 1529-1543.

32. Zimmermann T, Bordeanu N, Strub E (2010) Properties of nanofibrillated cellulose from different raw materials and its reinforcement potential. Carbohydr Polym 79(4):1086- 1093

\section{Figures}
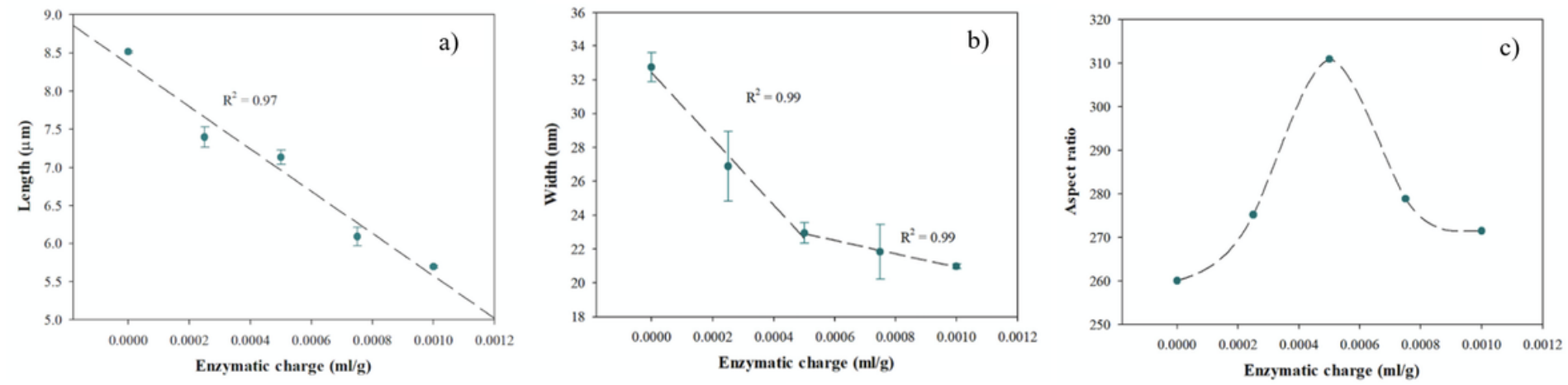

\section{Figure 1}

Morphological characteristics of the CNFs as a function of the enzyme charge in the second enzyme pretreatment. a) length, b) width, and c) aspect ratio. 

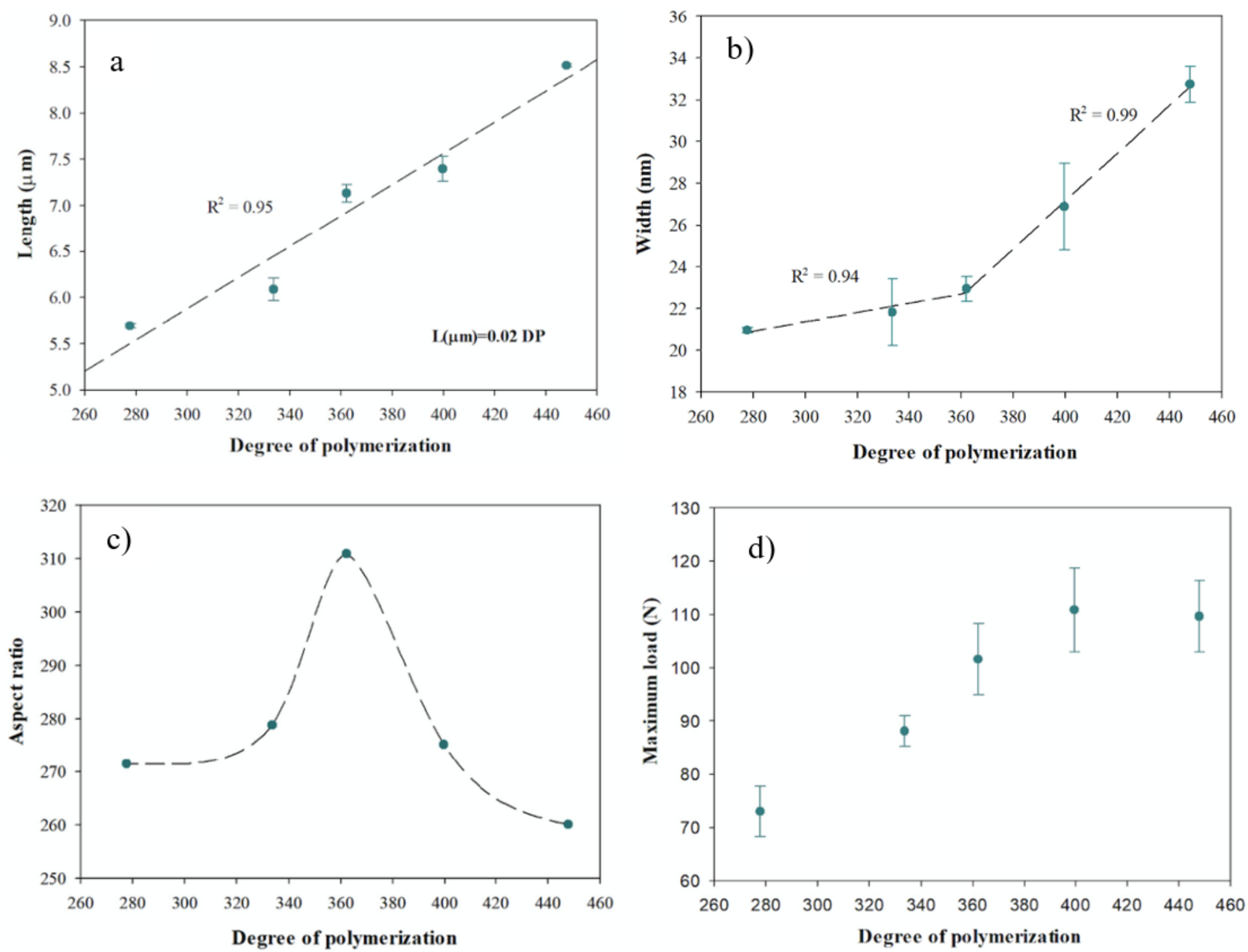

Figure 2

Morphological characteristics of CNFs and resistance of CNF films depending on the degree of polymerization. a) length, b) width, c) aspect ratio, and d) maximum load. 